\title{
Heinrich event 1: an example of dynamical ice-sheet reaction to oceanic changes
}

\author{
J. Álvarez-Solas ${ }^{1,2}$, M. Montoya ${ }^{1,3}$, C. Ritz ${ }^{4}$, G. Ramstein ${ }^{2}$, S. Charbit ${ }^{2}$, C. Dumas ${ }^{2}$, K. Nisancioglu ${ }^{5}$, T. Dokken ${ }^{5}$, and \\ A. Ganopolski ${ }^{6}$ \\ ${ }^{1}$ Dpto. Astrofísica y Ciencias de la Atmósfera, Universidad Complutense, Madrid, Spain \\ ${ }^{2}$ LSCE/IPSL, CEA-CNRS-UVSQ, UMR1572, CEA Saclay, Gif-sur-Yvette, France \\ ${ }^{3}$ Instituto de Geociencias (UCM-CSIC), Facultad de Ciencias Físicas, Madrid, Spain \\ ${ }^{4}$ Laboratoire de Glaciologie et de Géophysique de l'Environnement, CNRS, Saint Martin d'Hères, France \\ ${ }^{5}$ Bjerknes Centre for Climate Research, Bergen, Norway \\ ${ }^{6}$ Potsdam Institute for Climate Impact Research, Potsdam, Germany
}

Received: 3 May 2011 - Published in Clim. Past Discuss.: 12 May 2011

Revised: 19 September 2011 - Accepted: 6 October 2011 - Published: 29 November 2011

\begin{abstract}
Heinrich events, identified as enhanced ice-rafted detritus (IRD) in North Atlantic deep sea sediments (Heinrich, 1988; Hemming, 2004) have classically been attributed to Laurentide ice-sheet (LIS) instabilities (MacAyeal, 1993; Calov et al., 2002; Hulbe et al., 2004) and assumed to lead to important disruptions of the Atlantic meridional overturning circulation (AMOC) and North Atlantic deep water (NADW) formation. However, recent paleoclimate data have revealed that most of these events probably occurred after the AMOC had already slowed down or/and NADW largely collapsed, within about a thousand years (Hall et al., 2006; Hemming, 2004; Jonkers et al., 2010; Roche et al., 2004), implying that the initial AMOC reduction could not have been caused by the Heinrich events themselves.

Here we propose an alternative driving mechanism, specifically for Heinrich event 1 (H1; 18 to $15 \mathrm{ka} \mathrm{BP})$, by which North Atlantic ocean circulation changes are found to have strong impacts on LIS dynamics. By combining simulations with a coupled climate model and a three-dimensional ice sheet model, our study illustrates how reduced NADW and AMOC weakening lead to a subsurface warming in the Nordic and Labrador Seas resulting in rapid melting of the Hudson Strait and Labrador ice shelves. Lack of buttressing by the ice shelves implies a substantial ice-stream acceleration, enhanced ice-discharge and sea level rise, with peak
\end{abstract}

Correspondence to: J. Álvarez-Solas (jorge.alvarez.solas@ fis.ucm.es) values $500-1500 \mathrm{yr}$ after the initial AMOC reduction. Our scenario modifies the previous paradigm of $\mathrm{H} 1$ by solving the paradox of its occurrence during a cold surface period, and highlights the importance of taking into account the effects of oceanic circulation on ice-sheets dynamics in order to elucidate the triggering mechanism of Heinrich events.

\section{Introduction}

A major effort has been devoted in the last decade in order to understand rapid glacial climate variability as registered in many climatic archives. Greenland ice core records indicate that the last glacial period was punctuated by more than 20 abrupt warmings larger than $10 \mathrm{~K}$ (Dansgaard-Oeschger events) followed by progressive cooling (Dansgaard et al., 1993; Grootes et al., 1993). As revealed by the study of marine sediment cores in the North Atlantic, six of the temperature minima in Greenland were also coeval with unusual amounts of ice rafted debris (IRD) originating primarily from the areas around Hudson Bay (Bond et al., 1992). Several mechanisms have been proposed to explain these anomalous ice discharge events, known as Heinrich events. The first considers these to be internal oscillations of the Laurentide ice sheet (LIS) associated with alterations of basal conditions (MacAyeal, 1993; Calov et al., 2002). A sudden break-up of ice shelves has also been implicated via atmospheric warming (Hulbe et al., 2004) or tidal effects (Arbic et al., 2004).

Published by Copernicus Publications on behalf of the European Geosciences Union. 
Evidence for strongly reduced NADW formation during Heinrich events (Sarnthein et al., 1994) has led to the interpretation that massive iceberg discharge caused important disruptions in the Atlantic Ocean circulation. Yet, recent paleoclimate data have revealed that during H1 (ca. $17.5 \mathrm{ka} \mathrm{BP}$ ) peak IRD discharge from the LIS occurred several hundred years after the AMOC had slowed down or largely collapsed (Hall et al., 2006). Furthermore, H1 and earlier H events show the largest IRD peaks occurring several hundred years after the onset of the cold period (Hemming, 2004; Jonkers et al., 2010; Roche et al., 2004), suggesting that the initial AMOC reduction could not have been caused by the Heinrich events themselves.

The identification of additional petrological changes in IRD indicates that for some of the Heinrich layers, the initial increase in IRD flux is associated with icebergs of European origin predating the LIS surges (Hemming, 2004). Such precursor events have been suggested to play a mechanistic role in the initiation of the AMOC reduction (Hall et al., 2006) as well as in the LIS collapse (Grousset et al., 2000). Ocean-ice-sheet interactions including sea-level rise (Levermann et al., 2005) and subsurface temperature warming (Mignot et al., 2007) as a result of NADW reduction have been proposed both to amplify the initial AMOC reduction and the breakup of ice shelves. Lack of buttressing by the ice-shelves would result in substantial ice-stream acceleration leading to increased iceberg production and, thus, to the proper Heinrich event (Álvarez-Solas et al., 2010b; Hulbe, 2010; Flückiger et al., 2006; Shaffer et al., 2004). This hypothesis is supported by observations in Antarctica that illustrate the relevance of ocean-ice-sheet interactions for understanding recent changes in ice stream velocities (Rignot et al., 2004; Scambos et al., 2004). Here these ideas are assessed quantitatively by investigating the potential effects of oceanic circulation changes on LIS dynamics at the time of $\mathrm{H} 1$.

\section{Model setup and experimental design}

We combined results of simulations with the climate model CLIMBER-3 $\alpha$ (Montoya et al., 2005; Montoya and Levermann, 2008) and the GRISLI three-dimensional ice-sheet model of the Northern Hemisphere (Ritz et al., 2001; Peyaud et al., 2007).

Concerning CLIMBER- $3 \alpha$, the starting point is a simulation of the Last Glacial Maximum (LGM, ca. 21 ka before present (BP)). The forcing and boundary conditions follow the specifications of the Paleoclimate Modelling Intercomparison Project Phase II (PMIP2, http://pmip2.lsce.ipsl.fr), namely: changes in incoming solar radiation, reduced greenhouse gas concentration (since our model only takes $\mathrm{CO}_{2}$ into account, an equivalent atmospheric $\mathrm{CO}_{2}$ of $167 \mathrm{ppmv}$ concentration was used to account for the lowered $\mathrm{CH}_{4}$ and $\mathrm{N}_{2} \mathrm{O}$ atmospheric $\mathrm{CO}_{2}$ concentration), the ICE-5G ice-sheet reconstruction (Peltier, 2004) and changes in land-sea mask consistent with the latter, and an increase of 1 psu to account for the $\sim 120 \mathrm{~m}$ sea-level lowering. Vegetation and other land-surface characteristics as well as river-runoff routing were unchanged with respect to the present-day control run (Montoya et al., 2005). Due to the coarse resolution of its atmospheric component, the surface winds simulated by the model are not adequate to force the ocean. For experiments representing modest deviations with respect to the preindustrial climate, an anomaly model was implemented in which the wind-stress anomalies relative to the control run are computed and added to climatological data (Montoya et al., 2005). This approach, however, is not appropriate for a considerably different climate such as that of the LGM. Recently, the sensitivity of the glacial AMOC to wind-stress strength was investigated by integrating the model to equilibrium with the Trenberth et al. (1989) climatological surface wind-stress vector field scaled by a globally constant factor $\alpha \in[0.5,2]$ (Montoya and Levermann, 2008). The simulated LGM AMOC strength was found to increase continuously with surface wind-stress up to $\alpha_{c} \equiv 1.7$. In this wind-stress regime, NADW formation takes place south of the Greenland-Scotland ridge. At $\alpha=\alpha_{c} \equiv 1.7$ a threshold associated with a drastic AMOC increase of more than $10 \mathrm{~Sv}$ and a northward shift of deep water formation north of the Greenland-Scotland ridge (GSR) was found. Thus, for $\alpha=\alpha_{c} \equiv 1.7$ the model exhibits two steady states, with weak and strong AMOC as well as GSR overflow, respectively. The strong AMOC state (LGM1.7-strong) is associated with a stronger North Atlantic current and poleward heat transport, reduced sea-ice cover in the North Atlantic and increased surface temperatures relative to LGM1.7-weak (see also Montoya and Levermann, 2008). Although the CLIMAP (1976) sea-surface temperature reconstruction indicates that the Nordic Seas were perennially covered with sea-ice during the LGM, more recent data suggest instead that this region was seasonally ice-free (Hebbeln et al., 1994; Sarnthein et al., 2003; De Vernal et al., 2006; MARGO, 2009). Thus, our LGM1.7-strong climate simulation is in better agreement with these data and provides a better representation of the LGM climate than LGM-1.7weak, and is herein taken as the starting point for all simulations.

The GRISLI ice-sheet model is nowadays the only one able to properly deal with both grounded and floating ice on the paleo-hemispheric-scale, since it explicitly calculates the Laurentide grounding line migration, ice stream velocities, and ice shelf behaviour. Inland ice deforms according to the stress balance using the shallow ice approximation (Morland, 1984; Hutter, 1983). Ice shelves and dragging ice shelves (ice streams) are described following MacAyeal (1989). This 3-D ice-sheet-ice-shelf model has been developed by Ritz et al. (2001) and validated over Antarctica (Ritz et al., 2001; Philippon et al., 2006; Álvarez-Solas et al., 2010a) and over Fennoscandia (Peyaud et al., 2007). A comprehensive description of the model is given by these authors. In order to 
obtain realistic Northern Hemisphere ice sheets at the time of H1, GRISLI was forced throughout the last glacial cycle by the climatic fields resulting from scaling the climate anomalies simulated by the CLIMBER- $3 \alpha$ model for LGM and present conditions by an index derived from the Greenland GRIP $\delta^{18} \mathrm{O}$ ice core record (Dansgaard et al., 1993; Supplement). This method has been used in many studies to simulate the evolution of the cryosphere during the last glacial cycle (Charbit et al., 2007). Note, however, that the experimental setup used here does not resolve the coupled effects between ice-sheet-ice-shelf dynamics and atmospheric and oceanic circulations. Concerning the ice-sheet reconstruction, it implies that the dependence of atmospheric stationary waves on ice-sheet elevation changes is not considered, the ice-albedo effect could be overestimated and temperature and precipitation changes occur synchronously along the different ice-sheets all over the last glacial period. It also implies that the direct effects of the simulated Labrador ice shelf on the Labrador Sea deep water formation can not be accounted for here. In spite of the current limitations in the experimental setup, the simulated Northern Hemisphere ice-sheet characteristics for $18 \mathrm{kaBP}$ (Fig. 1) show good agreement with reconstructions in terms of volume and geographical distribution, and it agrees remarkably well with these in terms of ice-stream locations (Winsborrow et al., 2004).

\subsection{Implementation of the basal dragging dependence on sediments}

An important improvement present in GRISLI with respect to models which are only based on the Shallow Ice Approximation (SIA) is the fact that areas where basal ice is at the melting point, whereby ice flow occurs in the presence of water, are treated in the model under the shallow ice shelf/stream approximation proposed by MacAyeal (1989), which allows for a more proper representation of ice streams than under the pure SIA. In this way, the ice-stream velocities depend on the basal dragging coefficients $\tau$ that are a function of the bedrock characteristics and effective pressure:

$$
\tau_{\mathbf{b}}=-v^{2} N \boldsymbol{U}_{\mathbf{b}}
$$

where $N$ represents the effective pressure (balance between ice and water pressure) and $v^{2}$ is an empirical parameter with a typical value of $0.910^{-5}$ that has been adjusted in order to fit the Antarctic simulated ice velocities to those given by satellite observation. However, this cannot be done for Northern Hemisphere glacial simulations. We decide to account for this uncertainty by considering a set of three different values of the $v^{2}$ parameter:

$v^{2}=1,2,10 \times 10^{-4}$ (dimensionless)

where $v^{2}$ represents the basal friction coefficient in ice streams.

Ice streams are therefore treated in GRISLI as ice shelves with basal dragging. The challenge consists of appropriately calculating the basal friction at each point. Areas in the presence of soft sediments will allow less friction than areas in which the basal ice is directly in contact with the bedrock. Here we accounted for this effect by allowing the presence of a potential ice stream only in regions with sufficiently thick sediments (Mooney et al., 1998).

\subsection{The basal melting computation}

It has been largely suggested that the processes allowing ice surges of the ice sheets and dramatic calving episodes are closely related with oceanic behaviour (Hulbe et al., 2004; Shaffer et al., 2004; Flückiger et al., 2008). The floating part of the ice sheets (ice shelves) constitutes the component where this link has more relevance. The mass balance of the ice shelves is determined by the ice flow upstream, surface melt water production, basal melting and calving. Basal melting under the ice shelves represents the biggest unknown parameter in paleoclimate simulations involving ice sheets and ice shelves. Beckmann and Goosse (2003) suggested a law to compute this basal melting rate based on the heat flux between the ocean and floating ice. This method is particularly helpful for regional ocean/ice shelves models. Following their equations, under present-day climate conditions, the net basal melting rate can be well constrained in highresolution coupled ocean-shelf models:

$B=\frac{\rho_{\mathrm{o}} c_{\mathrm{po}} \gamma_{T}}{\rho_{i} L_{i}}\left(T_{\mathrm{o}}-T_{\mathrm{f}}\right) A_{\mathrm{eff}}$,

where $T_{\mathrm{O}}$ is the (subsurface-) ocean temperature, $T_{\mathrm{f}}$ is the freezing point temperature at the base of the ice shelf and $A_{\text {eff }}$ is an effective area for melting. Basal melting resulting from this equation would be appropriate for a high-resolution ocean/ice shelf. However, this method remains controversial (Olbers and Hellmer, 2010) and due to the coarse ocean model resolution, the processes involved are not well resolved. Therefore, due to the time and spatial scales involved in our experiments, the latter expression can thus be rewritten as follows:

$B=\kappa\left(T_{\mathrm{o}}-T_{\mathrm{f}}\right)$.

To take the associated uncertainty into account, we simply explore the response of our model to a large values range of this parameter:

$\kappa=0.2,0.5,1 \mathrm{~m} \mathrm{yr}^{-1} \mathrm{~K}^{-1}$.

This parameter determines the magnitude of basal melting changes as a function of oceanic temperatures. The basal melting amplitude will determine not only the presence and thickness of ice shelves, but also the capability of ice sheets to advance over the coast (i.e. grounded line migration). Thus, starting from the last interglacial period $(130 \mathrm{kaBP})$, different values of $\kappa$ determine different configurations of the spatial distribution of the Northern Hemisphere ice sheets at the LGM. Note here for simplicity that the variations of 

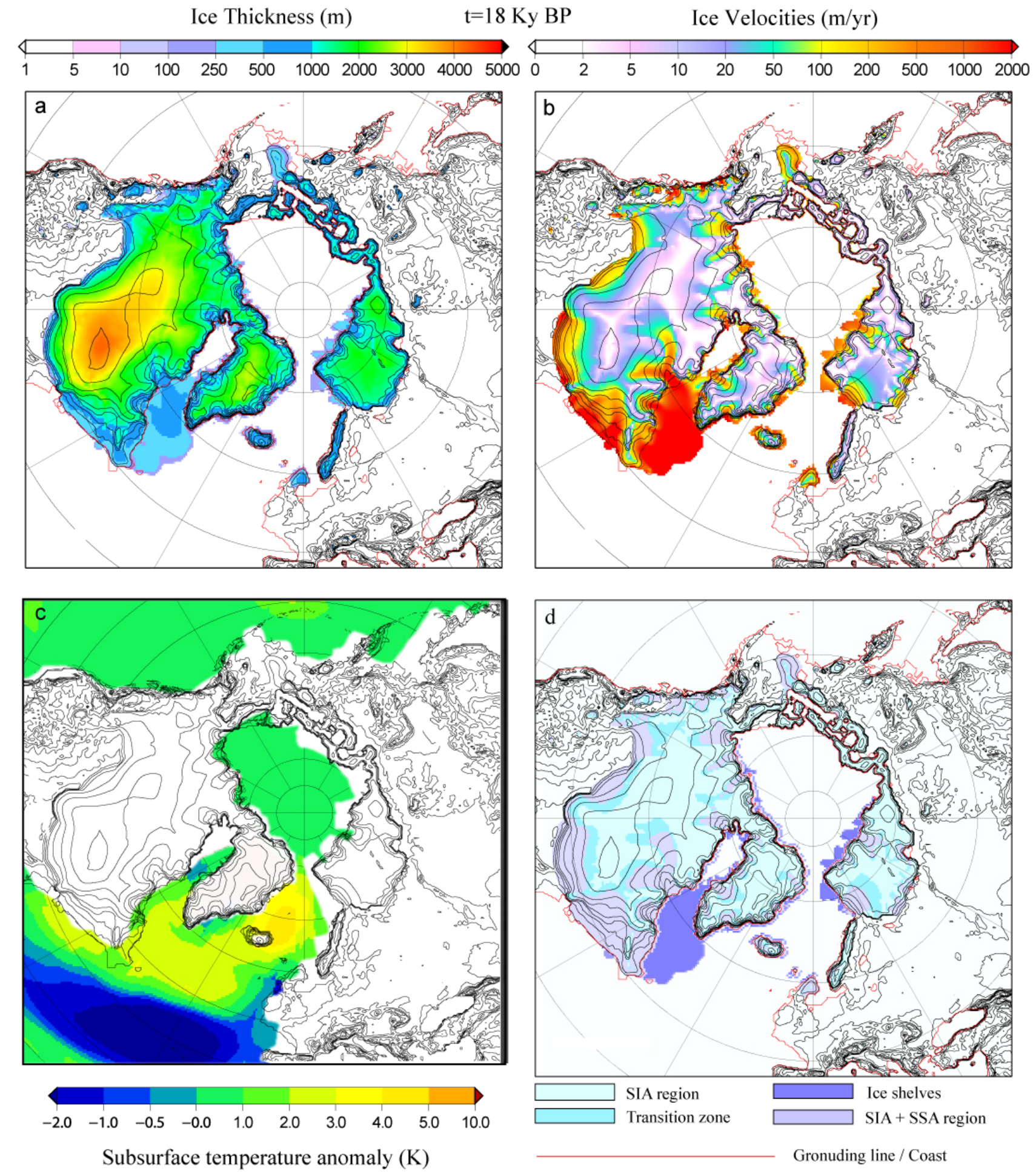

Fig. 1. Northern Hemisphere ice sheets simulated by the GRISLI model at $18 \mathrm{ka} \mathrm{BP}$, prior to Heinrich event 1 , in terms of ice thickness (a), ice velocities (b) and subsurface (550-1050 m) mean annual temperature anomaly (in K) in response to the shutdown of Nordic Seas deep water formation (c). This temperature anomaly and the corresponding ice-shelf basal melting has been considered during the period 18$17 \mathrm{ka} \mathrm{BP}$. Panel (d) illustrates the different parts of the ice sheet in terms of its dynamics. SIA and SSA mean Shallow Ice Approximation and Shallow Shelf Approximation respectively. 


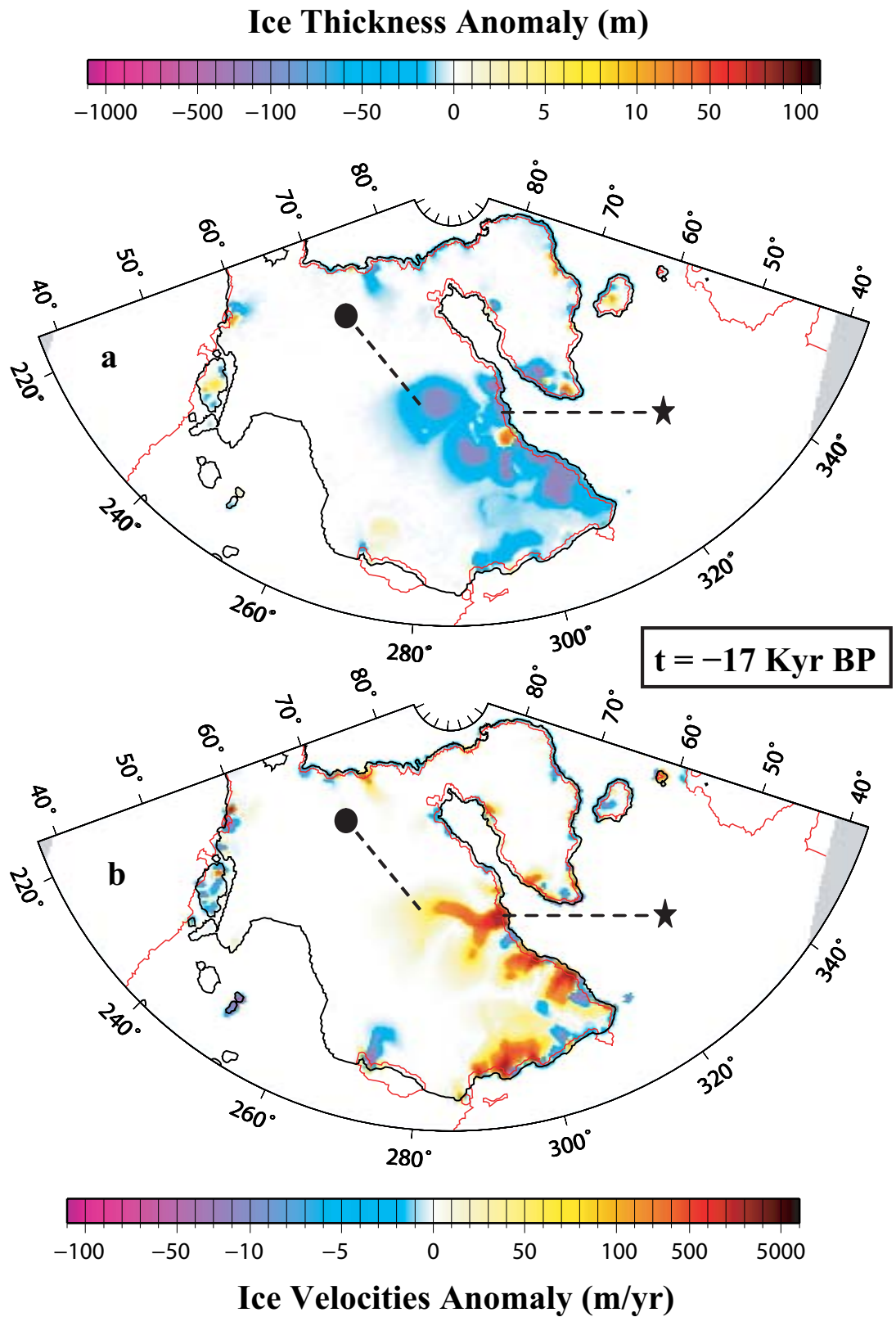

Fig. 2. Ice thickness (in $\mathrm{m}$ ) and velocity (in $\mathrm{m} \mathrm{yr}^{-1}$ ) anomalies of the Greenland and Laurentide ice sheets when accounting for the effects of the oceanic circulation changes (implying an oceanic subsurface warming) after one thousand years at $17 \mathrm{ka}$ BP. The star and circle indicate the location of the Hudson Strait ice stream mouth and source, respectively.

the annual mean subsurface ocean temperature $T_{\mathrm{o}}$ throughout the last glacial cycle were neglected. Thus, the mean annual subsurface ocean temperature $T_{\mathrm{o}}$ corresponding to the LGM snapshots was used instead of an interpolated value based on the GRIP $\delta^{18} \mathrm{O}$ as is done for the atmospheric fields.

The above mentioned range of values considered for $\kappa$ and $v^{2}$ generates a set of $n=9(3 \times 3)$ simulations, corresponding to all possible combinations of values of the former parameters, each of which yields a different configuration of the Northern Hemisphere ice sheets at $18 \mathrm{kaBP}$, prior to Hein- rich event 1 . This method allows us to explore the sensitivity of the initial ice-sheet configuration to the former parameters and to assess the interaction between ice sheets and ocean circulation over a wide phase space of the system initial conditions. The sensitivity of the model to all parameter values is treated in the Supplementary Information, while the results analyzed below correspond to one given parameter configuration $\left(\kappa=0.5 \mathrm{~m} \mathrm{yr}^{-1} \mathrm{~K}^{-1} ; v^{2}=2 \times 10^{-4}\right)$, considered as the standard. 


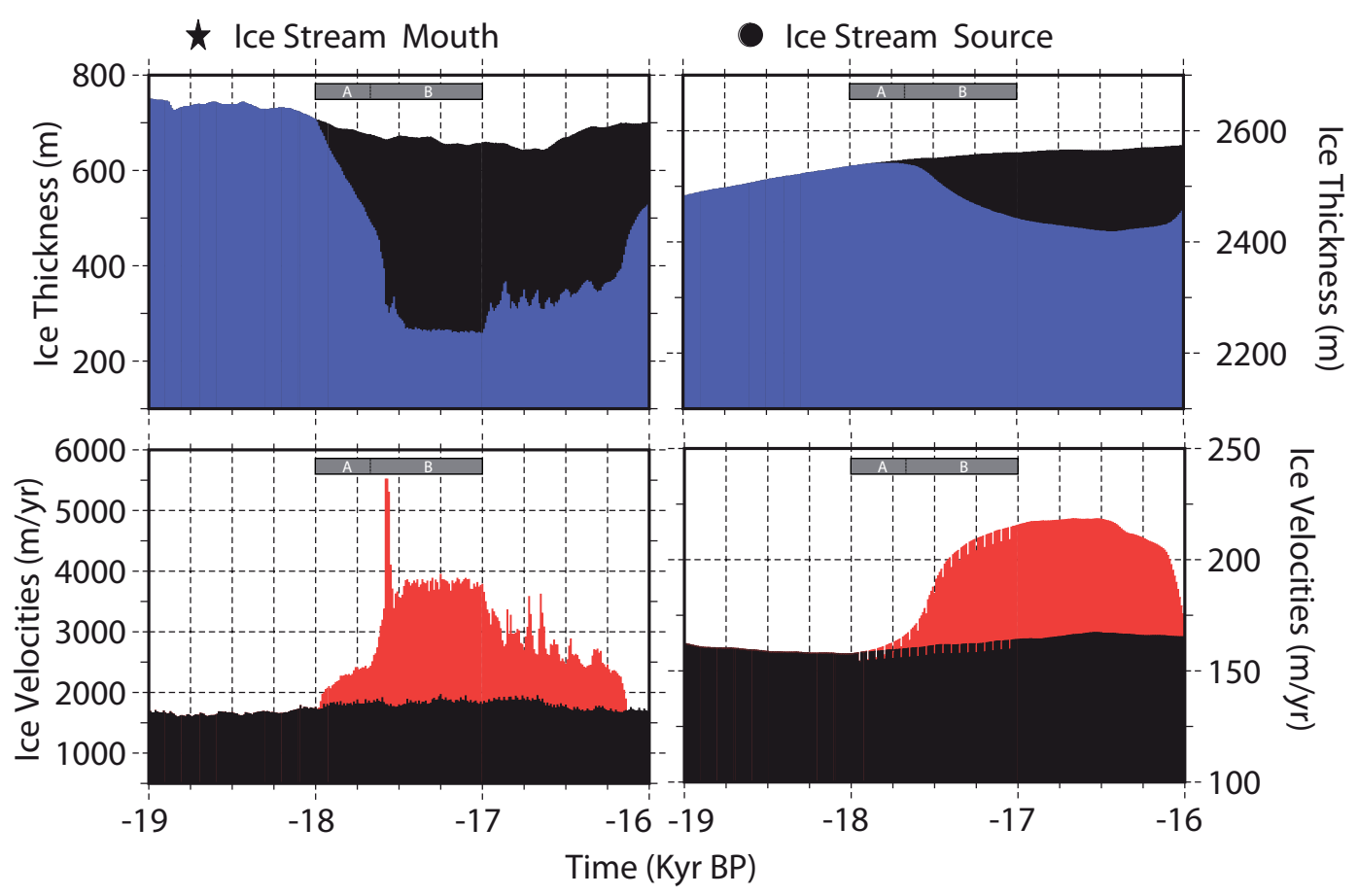

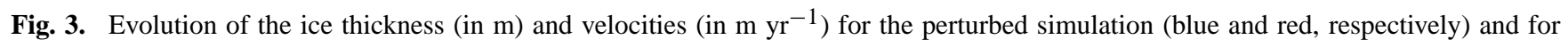
the standard simulation without accounting for oceanic circulation changes (black). The gray rectangle indicates the duration of the oceanic subsurface warming. Within this rectangle, (A) shows the phase of ice shelf breaking and (B) indicates the period of missing ice shelf (i.e. more than $95 \%$ of surface reduction).

\section{Results}

\subsection{Oceanic subsurface warming}

Our results show that the ice retreat first started over Fennoscandia between 20 and $18 \mathrm{kaBP}$. Melting of the Fennoscandian ice sheet resulted in enhanced freshwater flux (sea level rise equivalent of around $2 \mathrm{~m}$ ) into the Nordic Seas. To assess the impact of the latter on the North Atlantic ocean circulation, several experiments were carried out by imposing comparable freshwater fluxes on the glacial simulation with the climate model. Freshwater fluxes with a fixed amplitude of $0.2 \mathrm{~Sv}$ with varying duration $(\Delta t)$ between 10 and $100 \mathrm{yr}$ were added between $61^{\circ} \mathrm{N}-63^{\circ} \mathrm{N}$ and $6^{\circ} \mathrm{W}-$ $5^{\circ} \mathrm{E}$, representing a sea-level rise between ca. 0.2 and $2 \mathrm{~m}$. In the glacial simulation, NADW formation takes place in the Nordic and Labrador Seas (not shown). For the weakest freshwater flux perturbations $(\Delta t \leq 20 \mathrm{yr}$ ), NADW was reduced everywhere, but for $\Delta t>20 \mathrm{yr}$, it was inhibited everywhere north of $50^{\circ} \mathrm{N}$, thereby increasing sea ice extent and leading to the formation of a strong halocline with presence of warmer subsurface waters, especially in the Nordic Seas (Fig. 1). This simulated pattern fully agrees with marine proxies in Nordic Seas (Clark et al., 2007; Dokken and Jansen, 1999).

This subsurface temperature anomaly (Fig. 1c) propagates on advective timescales (within a few decades; see Supple- ment animations) toward the Labrador Sea. To investigate its potential effects on the LIS, we carried out two main sets of cryospheric experiments in which the climate fields (surface air temperature and precipitation) of the state with weakened NADW were used to force the GRISLI ice sheet/ice shelf model. In the first case, subsurface temperature changes associated with changes in the ocean circulation were taken into account, while in the second case, these were neglected. The comparison between both simulations allows us to isolate and quantify the effects of the oceanic forcing on the LIS dynamics.

\subsection{Ice-shelf collapse and ice-stream acceleration}

In the first case, the enhanced heat flux from the ocean to the ice due to subsurface warming induces an increase of the basal melt below the Labrador ice shelf (Fig. 1). The reduced shelf thickness increases the calving rate substantially. The breakup of the large ice shelf is very fast (within decades), resulting in a first pronounced peak of ice discharge (from iceberg calving) and freshwater flux into the ocean (from basal melting) (Fig. 4, blue). The ice shelf disintegration has dynamical implications far inland. Ice streams located at the mouth of Hudson Strait and south of Greenland were buttressed by the Labrador ice shelf embayment. Removing this buttressing effect by the ice shelf disintegration results in a sudden acceleration of flow in these ice streams. Comparable 


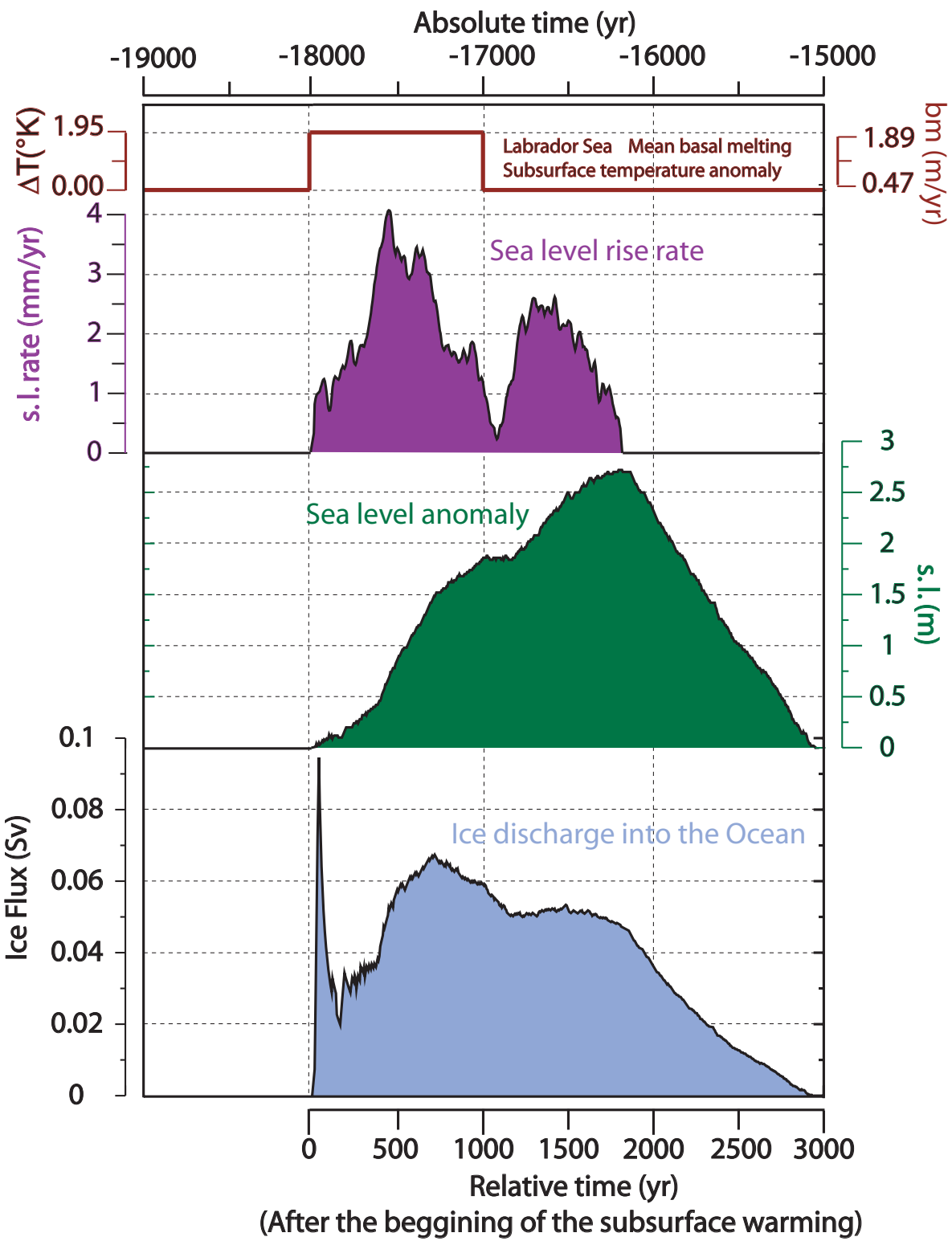

Fig. 4. Labrador Sea subsurface temperature anomaly (in $\mathrm{K}$ ) and basal melting (in $\mathrm{m} \mathrm{yr}^{-1}$; red curve), sea level rise rate (in mm $\mathrm{yr}^{-1}$ ), sea level rise $(\mathrm{m})$ and iceberg calving (in Sv) derived from the effects of the oceanic subsurface warming on the dynamic behavior of the Laurentide ice sheet.

to recent observations on the Antarctic Peninsula after the breakup of the Larsen B ice shelf, ice velocities in the coastal LIS increase by a factor 4 , shifting from ca. $1000 \mathrm{~m} \mathrm{yr}^{-1}$ to $4000 \mathrm{~m} \mathrm{yr}^{-1}$ (Fig. 2).

The duration of this process is considerably longer than for the ice shelf disintegration which caused it. The force balance change, associated with the absence of longitudinal stresses previously exerted by the ice shelf against the continental edges, propagates inland along the ice streams up to their source (located at Hudson Bay in the case of the Hudson Strait ice stream). The ice discharge reaches a maximum at the mouth of the Hudson Strait ice stream around
$700 \mathrm{yr}$ after the beginning of the subsurface warming in the Labrador Sea (Fig. 3), corresponding to the second peak in iceberg discharge into the Atlantic Ocean (Fig. 4). However, the enhanced ice flow surge is simulated for a time period largely exceeding the oceanic subsurface warming duration, translating in a second peak in sea level rise rate and an extended plateau of ice discharge after the main peak (see purple and gray curves respectively in Fig. 4). The time scale is set by the time needed by the ice streams to firstly respond to the perturbed longitudinal stresses at their mouth until their source $(\sim 1000 \mathrm{~km}$ far inland) and then to equilibrate under the new force balance at the grounding line. 
Heinrich event 1

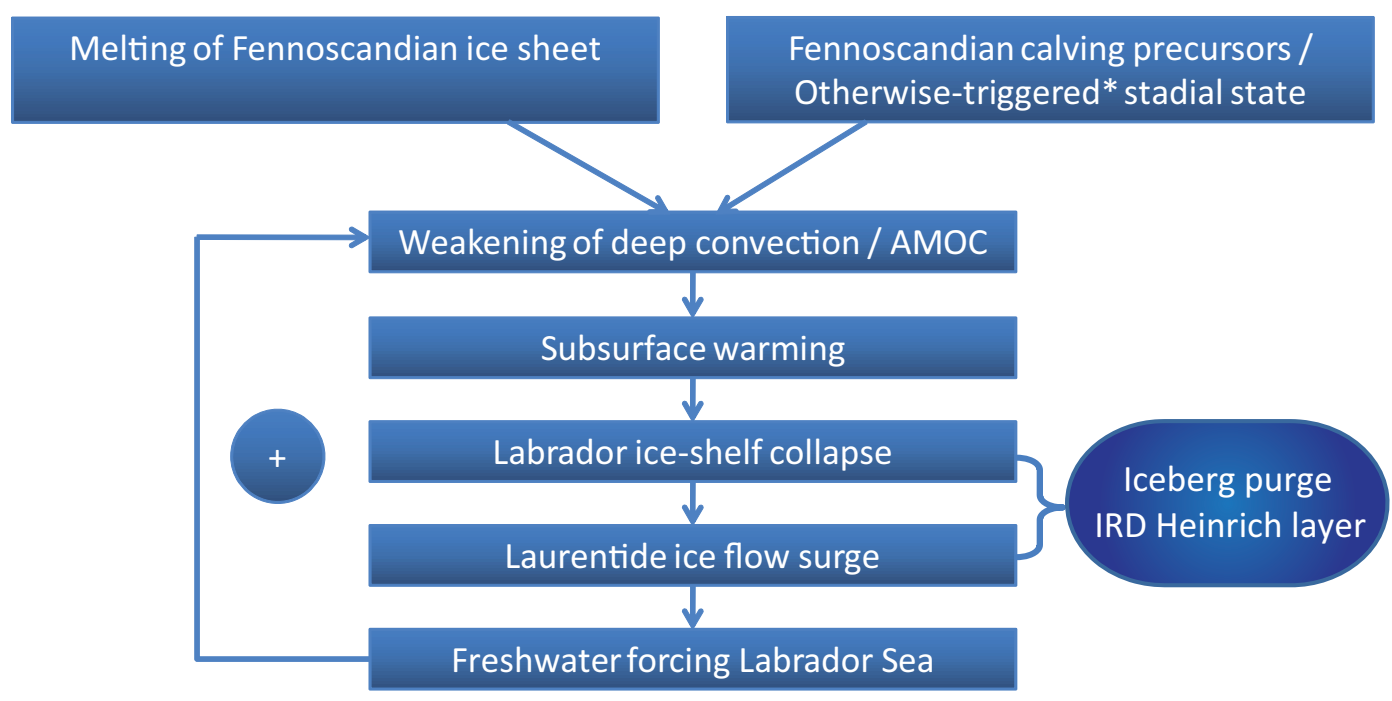

Fig. 5. Schematics of the triggering mechanism of Heinrich events proposed here. *Note that, for H1, an earlier fennoscandian freshwater flux has been identified while fennoscandian precursors are still debated for the other HEs. However, these do not represent a necessary condition for the mechanism suggested here.

Large portions of the eastern LIS, where ice dynamics are mainly controlled by the above mentioned ice streams, suffer an important reduction in their thickness (more than $500 \mathrm{~m}$ in the Hudson Bay/Strait area), illustrating the relevance of considering the dynamic coupling between ice streams and ice shelves. Note that when neglecting oceanic temperatures changes (Fig. 3, black) or when a constant basal melting rate is applied the ice sheet model does not generate any selfsustained ice discharge. As noted above, this is a critical point for the triggering mechanism of Heinrich Events.

\section{Discussion}

It is important to highlight that under the mechanism proposed here, the iceberg discharge configuring $\mathrm{H} 1$ is not responsible for the initial NADW reduction. However, the associated freshwater discharge from the $\mathrm{H} 1$ event could further impact deep water formation, eventually leading to its shutdown. This configures a feedback mechanism (Fig. 5) that explains why during Heinrich stadials the AMOC appears more perturbed than during non-Heinrich stadials, as suggested by proxies (Hemming, 2004, and references therein).

Here we have shown that a previously weakened meridional oceanic circulation is needed to create the subsurface water anomalies that will perturb ice shelves and therefore trigger the required ice surges. Although the focus here is on $\mathrm{H} 1$, the initial requirement is potentially valid for all six Heinrich Events, given the fact that they all occur during a cold stadial period. The mechanisms that led the ocean into a stadial condition during the other Heinrich events are not discussed here. As summarized in Fig. 5, for H1 we assume, as suggested by proxies (Hall et al., 2006), that the early deglaciation of the Fennoscandian ice sheet resulted in enhanced freshwater fluxes to the North Atlantic, forcing the ocean into a state with weak Atlantic overturning and NADW south of Iceland, similar to a stadial period. The assumption under which the ocean needs to shift into a stadial condition as a precursor for triggering Heinrich Events solves the paradox raised by previous studies (Bond and Lotti, 1995; Shaffer et al., 2004; Clark et al., 2007; Álvarez-Solas et al., 2010b).

\section{Conclusions}

To summarize, we propose that $\mathrm{H} 1$ was triggered by warm North Atlantic subsurface waters resulting from reduced NADW formation. Under this new mechanism, the dynamic ocean-ice-sheet interaction leads to both cold surface conditions and warm subsurface waters, which are crucial for ice shelf breakup. Reducing their buttressing effect induces a large iceberg discharge and an ice-stream acceleration that tranlates into up to $2 \mathrm{~m}$ of sea level rise, with a maximum rate of $4 \mathrm{~mm} \mathrm{yr}^{-1}$ (the same order of magnitude as the present-day anthropically-induced rise, with all effects included) only by dynamical reaction of the Laurentide ice sheet.

Our results provide a new consistent mechanism to trigger $\mathrm{H} 1$ composed of a sequence of events from initial subsurface warming of the ocean to the final massive ice purge well after the initial NADW reduction, in agreement with data. 


\section{Supplementary material related to this article is available online at: http://www.clim-past.net/7/1297/2011/ cp-7-1297-2011-supplement.zip.}

Acknowledgements. We thank Y. Donnadieu, D. Paillard, D. Roche, F. Remy, F. Pattyn, A. Robinson and E. Lucio for helpful discussions, and two anonymous referees and the editor André Paul who helped to improve the manuscript. Figure 5 of this article is based on a similar figure suggested by referee \#2. We are also greatful to the PalMA group for useful comments and suggestions. This work was funded under the MOVAC and SPECT-MORE projects. J. A-S was also funded by the Spanish programme of the International Campus of Excellence (CEI).

Edited by: A. Paul

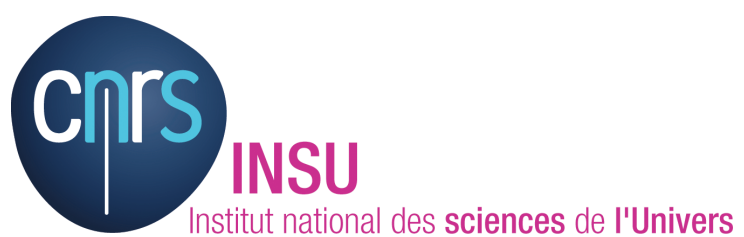

The publication of this article is financed by CNRS-INSU.

\section{References}

Álvarez-Solas, J., Charbit, S., Ramstein, G., Paillard, D., Dumas, C., Ritz, C., and Roche, D.: Millennial-scale oscillations in the Southern Ocean in response to atmospheric $\mathrm{CO}_{2}$ increase, Global Planet. Change, 76, 128-136, doi:10.1016/j.gloplacha.2010.12.004, 2010a.

Álvarez-Solas, J., Charbit, S., Ritz, C., Paillard, D., Ramstein, G., and Dumas, C.: Links between ocean temperature and iceberg discharge during Heinrich events, Nat. Geosci., 3, 122-126, 2010b.

Arbic, B., MacAyeal, D., Mitrovica, J., and Milne, G.: PalaeoclimateOcean tides and Heinrich events, Nature, 432, 460, doi:10.1038/432460a, 2004.

Beckmann, A. and Goosse, H.: A parameterization of ice shelfocean interaction for climate models, Ocean Model., 5, 157-170, 2003.

Bond, G. and Lotti, R.: Iceberg Discharges into the North Atlantic on Millennial Time Scales During the Last Glaciation, Science, 267, 1005-1010, 1995.

Bond, G., Heinrich, H., Broecker, W., Labeyrie, L., McManus, J., Andrews, J., Huon, S., Jantschik, R., Clasen, S., Simet, C., Tedesco, K., Klas, M., Bonani, G., and Ivy, S.: Evidence for massive discharge of icebergs into the North Atlantic Ocean during the last glacial, Nature, 360, 245-249, 1992.

Calov, R., Ganopolski, A., Petoukhov, V., Claussen, M., and Greve, R.: Large-scale instabilities of the Laurentide ice sheet simulated in a fully coupled climate-system model, Geophys. Res. Lett., 29, 2216, doi:10.1029/2002GL016078, 2002.

Charbit, S., Ritz, C., Philippon, G., Peyaud, V., and Kageyama, M.: Numerical reconstructions of the Northern Hemisphere ice sheets through the last glacial-interglacial cycle, Clim. Past, 3 , 15-37, doi:10.5194/cp-3-15-2007, 2007.

Clark, P., Hostetler, S., Pisias, N., Schmittner, A., and Meissner, K.: Mechanisms for an 7-kyr Climate and Sea-Level Oscillation During Marine Isotope Stage 3, Geoph. Monog.-American Geophysical Union, 173, 209, doi:10.1029/173GM15, 2007.

CLIMAP: Climate: Long-Range Investigation, Mapping, and Prediction (CLIMAP) Project Members, The surface of the ice-age, Science, 191, 1131-113, 1976.

Dansgaard, W., Johnsen, S., Clausen, H., Dahl-Jensen, D., Gundestrup, N., Hammer, C., Hvidberg, C., Steffensen, J., Sveinbjornsdottir, A., Jouzel, J., and Bond, G.: Evidence for general instability of past climate from a 250-kyr ice-core record, Nature, 364 218-220, 1993.

De Vernal, A., Rosell-Melé, A., Kucera, M., Hillaire-Marcel, C., Eynaud, F., Weinelt, M., Dokken, T., and Kageyama, M.: Comparing proxies for the reconstruction of LGM sea-surface conditions in the northern North Atlantic, Quaternary Sci. Rev., 25, 2820-2834, 2006.

Dokken, T. and Jansen, E.: Rapid changes in the mechanism of ocean convection during the last glacial period, Nature, 401, 458-461, 1999.

Flückiger, J., Knutti, R., and White, J.: Oceanic processes as potential trigger and amplifying mechanisms for Heinrich events, Paleoceanography, 21, PA2014, doi:10.1029/2005PA001204, 2006.

Flückiger, J., Knutti, R., White, J., and Renssen, H.: Modeled seasonality of glacial abrupt climate events, Clim. Dynam., 31, 633645, doi:10.1007/s00382-008-0373-y, 2008.

Grootes, P. M., Stuiver, M., White, J. W. C., Johnsen, S., and Jouzel, J.: Comparison of oxygen isotope records from the GISP2 and GRIP Greenland ice cores, Nature, 366, 552-554, 1993.

Grousset, F., Pujol, C., Labeyrie, L., Auffret, G., and Boelaert, A.: Were the North Atlantic Heinrich events triggered by the behavior of the European ice sheets?, Geology, 28, 123, doi: 10.1130/0091-7613(2000), 2000.

Hall, I. R., Moran, S. B., Zahn, R., Knutz, P. C., Shen, C. C., and Edwards, R. L.: Accelerated drawdown of meridional overturning in the late-glacial Atlantic triggered by transient pre- $\mathrm{H}$ event freshwater perturbation, Geophys. Res. Lett, 33, L16616, doi:10.1029/2006GL026239, 2006.

Hebbeln, D., Dokken, T., Andersen, E., Hald, M., and Elverhøi, A.: Moisture supply for northern ice-sheet growth during the Last Glacial Maximum, Nature, 309, 357-360, 1994.

Heinrich, H.: Origin and consequences of cyclic ice rafting in the northeast Atlantic Ocean during the past 130,000 years, Quaternary Res., 29, 142-152, 1988.

Hemming, S. R.: Heinrich events: Massive late Pleistocene detritus layers of the North Atlantic and their global climate imprint, Rev. Geophys, 42, RG1005, doi:10.1029/2003RG000128, 2004.

Hulbe, C.: Palaeoclimate: Extreme iceberg generation exposed, Nat. Geosci., 3, 80-81, 2010.

Hulbe, C., MacAyeal, D., Denton, G., Kleman, J., and Lowell, T.: Catastrophic ice shelf breakup as the source of Heinrich event icebergs, Paleoceanography, 19, PA1004, doi:10.1029/2003PA000890, 2004.

Hutter, K.: Theoretical glaciology: material science of ice and the mechanics of glaciers and ice sheets, Springer, 1983.

Jonkers, L., Moros, M., Prins, M., Dokken, T., Dahl, C., Dijkstra, N., Perner, K., and Brummer, G.: A reconstruction 
of sea surface warming in the northern North Atlantic during MIS 3 ice-rafting events, Quaternary Sci. Rev., 29, 1791-1800, doi:10.1016/j.quascirev.2010.03.014, 2010.

Levermann, A., Griesel, A., Hofmann, M., Montoya, M., and Rahmstorf, S.: Dynamic sea level changes following changes in the thermohaline circulation, Clim. Dynam., 24, 347-354, 2005.

MacAyeal, D.: Large-scale ice flow over a viscous basal sedimentTheory and application to ice stream B, Antarctica, J. Geophys. Res., 94, 4071-4087, 1989.

MacAyeal, D.: Binge/purge oscillations of the Laurentide ice sheet as a cause of the North Atlantic's Heinrich events, Paleoceanography, 8, 775-784, 1993.

MARGO: Constraints on the magnitude and patterns of ocean cooling at the Last Glacial Maximum, Nat. Geosci., 2, 127-132, 2009.

Mignot, J., Ganopolski, A., and Levermann, A.: Atlantic subsurface temperatures: response to a shut-down of the overturning circulation and consequences for its recovery, J. Climate, 20, 48844898, 2007.

Montoya, M. and Levermann, A.: Surface wind-stress threshold for glacial Atlantic overturning, Geophys. Res. Lett., 35, L03608, doi:10.1029/2007GL032560, 2008.

Montoya, M., Griesel, A., Levermann, A., Mignot, J., Hofmann, M., Ganopolski, A., and Rahmstorf, S.: The Earth System Model of Intermediate Complexity CLIMBER-3 $\alpha$. Part I: description and performance for present day conditions, Clim. Dynam., 25, 237-263, 2005.

Mooney, W., Laske, G., and Masters, T.: CRUST 5.1: A global crustal model at 5× 5, J. Geophys. Res., 103, 727-747, 1998.

Morland, L.: Thermomechanical balances of ice sheet flows, Geophys. Astro. Fluid, 29, 237-266, 1984.

Olbers, D. and Hellmer, H.: A box model of circulation and melting in ice shelf caverns, Ocean Dynam., 60, 141-153, 2010.

Peltier, W.: Global glacial isostasy and the surface of the ice-age Earth- The ICE-5 G(VM 2) model and GRACE, Ann. Rev. Earth Planet Sci., 32, 111-149, 2004.

Peyaud, V., Ritz, C., and Krinner, G.: Modelling the Early Weichselian Eurasian Ice Sheets: role of ice shelves and influence of ice-dammed lakes, Clim. Past, 3, 375-386, doi:10.5194/cp-3375-2007, 2007.
Philippon, G., Ramstein, G., Charbit, S., Kageyama, M., Ritz, C., and Dumas, C.: Evolution of the Antarctic ice sheet throughout the last deglaciation: A study with a new coupled climate-north and south hemisphere ice sheet model, Earth Planet. Sci. Lett., 248, 750-758, 2006.

Rignot, E., Casassa, G., Gogineni, P., Krabill, W., Rivera, A., and Thomas, R.: Accelerated ice discharge from the Antarctic Peninsula following the collapse of Larsen B ice shelf, Geophys. Res. Lett, 31, 18, doi:10.1029/2004GL020697, 2004.

Ritz, C., Rommelaere, V., and Dumas, C.: Modeling the evolution of Antarctic ice sheet over the last 420,000 years: Implications for altitude changes in the Vostok region, J. Geophys. Res.-Atmos., 106, 31943-31964, 2001.

Roche, D., Paillard, D., and Cortijo, E.: Constraints on the duration and freshwater release of Heinrich event 4 through isotope modelling, Nature, 432, 379-382, 2004.

Sarnthein, M., Winn, K., Jung, S., Duplessy, J., Labeyrie, L., Erlenkeuser, H., and Ganssen, G.: Changes in east Atlantic deepwater circulation over the last 30,000 years: Eight time slice reconstructions, Paleoceanography, 9, 209-209, 1994.

Sarnthein, M., Pflaumann, U., and Weinelt, M.: Past extent of sea ice in the northern North Atlantic inferred from foraminiferal paleotemperature estimates, Paleoceanography, 18, 1047, doi:10.1029/2002PA000771, 2003.

Scambos, T., Bohlander, J., Shuman, C., and Skvarca, P.: Glacier acceleration and thinning after ice shelf collapse in the Larsen B embayment, Antarctica, Geophys. Res. Lett, 31, 18, doi:10.1029/2004GL020670, 2004.

Shaffer, G., Olsen, S., and Bjerrum, C.: Ocean subsurface warming as a mechanism for coupling Dansgaard-Oeschger climate cycles and ice-rafting events, Geophys. Res. Lett, 31, L24202, doi:10.1029/2004GL020968, 2004

Trenberth, K., Olson, J., and Large, W.: A Global Ocean Wind Stress Climatology based on ECMWF Analyses, Tech. Rep. NCAR/TN-338+STR, National Center for Atmospheric Research, Boulder, Colorado, USA, 1989.

Winsborrow, M., Clark, C., and Stokes, C.: Ice streams of the Laurentide ice sheet, Géographie Physique et Quaternaire, 58, 269280, 2004. 